\title{
Embodied Simulation and a Few Remarks on the Philosophy of Language in Italy
}

\author{
Giusy Gallo \\ University of Calabria
}

\begin{abstract}
The debate on the state of the art of philosophy in Italy shows many differences from the three main currents of contemporary philosophy, namely deconstructionism, critical theory, and analytic philosophy. On one hand, the philosophical stance towards language, and on the other hand, the strong separation between science and philosophy are the distinctive features of the Italian thought. In particular, philosophy of language shows a fragmented framework in which current researches are an example for future studies on language and human nature. The basic idea behind the Philosophy of Language in Italy is that language has a biological and social nature. The aim of this paper is to give an account of the range of "bio" through a dialogue between philosophy and neuroscience. I will review the Italian research on mirror neurons with particular attention to the developments in embodied simulation proposed by Vittorio Gallese. I will underline the philosophical aspects of this neuroscientific theory, providing some remarks on intersubjectivity, intentions, and language. Finally, I will suggest future joint studies in neuroscience and the philosophy of language.
\end{abstract}

Keywords: mirror neurons, embodied simulation, intentions, language, Italian Thought, philosophy of language

\section{The Italian Philosophy of Language Today}

Over the last decade, Italian philosophy has achieved high visibility in the English-speaking world due to an increasing number of university courses, conferences, and book translations (in English and many other languages) as well as the fact that many Italian students and researchers are moving abroad. This growing interest in Italian philosophy is extremely difficult to explain for two reasons. First, we should be able to accurately determine the pattern of the theoretical issues that shapes the elements that fall under the label of Italian philosophy. Second, but related to the first point, we should be able to outline Italian philosophy according to certain differences from the main contemporary philosophical traditions, at the very least, those in Anglo-American analytic philosophy, hermeneutics, and critical theory. Contemporary philosophical traditions share language as a common denominator in their pivotal roles, except for Italian philosophy, in which the prominent attitude toward language has an anthropological nature (Esposito 2012).

The two points outlined above deal with the new Italian revival in foreign philosophies due to the dissemination of the so-called Italian Theory, namely a theoretical framework which is doubly articulated (Marramao 2014). On one hand, it follows French Theory in the path of deconstructionism, and on the other hand, it is the merging of philosophy and political theory with the key concepts of biopolitics and conflict.

Giusy Gallo, Ph.D., Department of Humanities, University of Calabria, Italy; main research field: Philosophy of Language, Semiotics and Philosophy of Mind. 
Philosophers like Giorgio Agamben, Paolo Virno, Roberto Esposito, Giacomo Marramao, and Massimo Cacciari are included in Italian Theory (or Italian Thought, as Roberto Esposito prefers to refer to it). However, without trying to find an Italian difference (Buongiorno and Lucci 2014; Gentili 2012) that justifies the new interest in Italian philosophy, the relevance of the adjective "Italian” must not be neglected.

One might erroneously think that there is an Italian perception of philosophy due to a national concept or feeling. The government and geographical entity known as Italy is a historically recent historical acquisition, that is, a particular circumstance that has hindered the building of a national consciousness and only one national language.

The quest of philosophy, inseparable from the historiographical and geopolitical misadventures of Italy, is not to look for a united concept in order to address the future of researchers and studies, but to consider that there is more than one philosophy, which means there must be an awareness of the existence of Italian philosophies. This perspective, to some extent, has been outlined in an issue of the journal Rue Descartes devoted to the state of the art of philosophy in Italy. The overall framework, pointed out by Paolo Quintili (2015) and Luca Paltrinieri (2015), shows that Italian philosophy is shaped by a number of geographical centres in which thinkers work; this condition could be the "Italian difference" ${ }^{, 1}$ that cannot be labelled simply as deterritorialization, but is the coexistence of different philosophical styles, created in different research centres and schools.

The richness of the Italian philosophical style deals also with the question of the (lack of a national) language from Dante onwards, resulting in the development of an attitude towards the study of language and languages. What is at issue here, then, is the philosophical stance on language (Cimatti 2014, 2015; Cimatti and Piazza 2016; Esposito 2014, 2015).

In 1956, La Sapienza University in Rome began to teach the Philosophy of Language as a university course $^{2}$ focused on the history of linguistic theories. The teaching assignment was appointed to Antonino Pagliaro and after to Tullio De Mauro. Since then, the Philosophy of Language has been taught at many other Italian universities: Torino, Milano, Trieste, Bologna, Salerno, Lecce, and the University of Calabria. In 1994, a group of academics founded the Italian Society of Philosophy of Language, whose members meet once a year for a national conference.

In Italy, considering the schools and the researches, one might articulate the Philosophy of Language from three perspectives, generally recognized as: first, a philosophy of language that is interested in historical and theoretical issues on language and languages and closer to the main idea of general linguistics (Saussure 1922); second, semiotics; and third, an analytic philosophy of language. ${ }^{3}$

The articulation of philosophy of language in Italy might be considered one of the distinctive features of this research field. Stancati (2015), recalling the idea that Italian thought is rooted in life and history according to Esposito, questioned the opportunity to reread the Italian philosophy of language in that light because of the necessary eclipse of the scientific object of the discipline, namely language and languages.

It is clear that there is no way to indicate a prevailing feature of the Philosophy of Language in Italy. This multifaceted framework clearly emerges from the issue devoted to The Philosophy of Language in Italy published by the Rivista Italiana di Filosofia del Linguaggio ${ }^{4}$ in July 2015. Other than some articles focusing on the relationship between Philosophy of Language and Aesthetics, Hermeneutics and Anthropology, and Rhetoric and Pragmatics, most articles are concerned with the so-called Italian Theory-operaism, the philosophy of Giorgio Agamben and Paolo Virno. 
A brief analysis of the issues devoted to the philosophy in Italy published in Rue Descartes and in Rivista Italiana di Filosofia del Linguaggio shows that one of the basic ideas behind the Philosophy of Language in Italy (Cimatti 2015; Ferretti 2015; Stancati 2015) is that language has a biological and social nature, even when this relation exploits the wide concept of biopolitics.

I do not intend to put the Philosophy of Language in Italy inside the Italian Theory or Thought but to give an account of the range of "bio" through a dialogue between philosophy and neuroscience, referring to an attempt to exceed the separation between philosophy and science. In particular, the Italian research on mirror neurons is a sample of an interdisciplinary investigation which does not mark the separation between science and philosophy. Indeed, in this framework, philosophy of language in Italy is involved in the neurocognitive research on language. I will review the Italian research on mirror neurons ${ }^{5}$ with particular attention to the developments in embodied simulation proposed by Vittorio Gallese. I will underline the philosophical aspects of this neuroscientific theory, providing some remarks on intersubjectivity, intentions, and language. Finally, I will suggest future joint studies in neuroscience and the philosophy of language.

\section{The Mirror Neuron System}

In the 1990s, a cluster of motor neurons that fires when an individual both acts and observes the same action performed by another individual was discovered in the premotor cortex in the so-called F5 area of the brains of macaques (Gallese, Fadiga, Fogassi, and Rizzolatti 1996). Actions with a precise purpose, like grasping an object, and the observation of such actions activate this population of mirror neurons. It follows that a macaque that observes the action has the same motor activation as if he is going to plan the performance of the action. This is the classical description of the mirror mechanism, which clarifies the relationship between action detection and action prediction.

In subsequent research, the mirror mechanism was also recorded in the human brain. One might consider the opportunity to explain the relationship between perception and action from a neurophysiological perspective; experimental data support the role of the mirror neuron system in playing a determinant role in imitation, in empathy, intention understanding, and emotions.

Today we know that mirror neurons are multimodal neurons that fire both during motor task execution and during observation: "We see not only through the visual part of our brain, but also through our motor neuron system.” ${ }^{\prime 6}$ Mirror neurons are no longer considered just a cluster of motor neurons as they are involved in cognitive functions. Why are mirror neurons-which are neurons that regulate "motor cognition"-so interesting for scholars in the field of language sciences? It has been shown that the mirror neuron system also activates when an individual is listening to sentences with motor verbs; that is, mirror neurons play an important role in the understanding of sentences that describe actions: "Mirror neurons' activity reveals the existence of a mechanism through which perceived events as different as sounds, or images, are nevertheless coded as similar to the extent that they represent the assorted sensory aspects of the motor act's goal” (Gallese 2009, 521).

In this respect, I claim that philosophers of language, typically those who conceive their subject to be general linguistics (in the shadow of Saussure), should explore how biological features matter in the social nature of languages and language. Philosophically speaking, sociality and the concept of intentionality are at stake. $^{7}$ 


\section{Embodied Simulation and the Other}

\subsection{What Is Embodied Simulation}

The discovery of mirror neurons has led to an embodied approach to mental simulation ${ }^{8}$ because the activity of the mirror mechanism has been described in terms of simulation: "Embodied Simulation (ES) mainly aimed to account for basic social interactions by means of a neurobiologically plausible and theoretically unitary framework” (Gallese and Sinigaglia 2011, 512). Embodied simulation is the functional mechanism that regulates our social cognition, is decisive in order to give an account of human sociality and stated by our capability to emphasize. It is a mandatory, unconscious, and pre-reflexive mechanism. Gallese and Sinigaglia focused on the main feature of embodied simulation: "Simulation can also be used to retrodict mental states, that is, to identify which mental states led another individual to perform a given action” (Gallese and Sinigaglia 2011, 512). This kind of simulation is rooted in our brains so that it challenges the model of (mental) simulation in which our intentions and actions can be described only in terms of propositional attitude like beliefs and desires. However, this description of simulation can be compared to a proto-function in the mindreading process, with the consequent challenge of the propositional format versus the embodied format of simulation. Which features are peculiar to simulation? Before responding to this question, it is necessary to consider a concept of representation as conceived by the neuroscientists who work on embodied simulation: "[I]t refers to a particular type of content, generated by the relations that our situated and interacting brain-body system instantiates with the world of the others. Such content is prelinguistic and pretheoretical” (Gallese 2009, 524).

Simulation presents two main non-mutually exclusive features: resemblance and reuse. At present, I would like to put aside the issue of simulation as interpersonal resemblance, and focus on the feature of reuse. We speak about reuse when the aim of mental simulation as defined by the mirror mechanism is reused for other purposes. This means that we can represent and perform a motor action but we can also attribute the same motor purpose to other individuals. Reuse happens when the simulator and the person to whom the mental states are attributed share the same bodily resources. The opportunity to reuse one's own mental representations of mental states and processes in order to attribute them to others has an embodied nature. The reuse feature of embodied simulation partially represents the mindreading process.

For decades, the scientific community has accepted the explanation of mindreading given by the theory of mind (ToM). It seems that researchers would like to replace the ToM with embodied simulation theory. Is this possible? Through the concept of metapresentation, ToM sheds light on the cognitive human ability to represent-by means of inferences—others' mental states. The discovery of mirror neurons led to the consideration of the understanding of language, emotions, and others' actions through a process of mirroring or simulation. If it is true that embodied simulation aims to understand the intentions of the others, then it seems to be close to the goals of ToM. However, their analogies are only apparent: the mirror mechanism has neurobiological assumptions, whereas ToM has a propositional approach to the mental domain. We should remember that embodied simulation is linked to the mirror mechanism insofar as "We experience others as having experiences similar to ours" (Gallese 2013, 2955). In my opinion, the matter is not about the choice of a bodily format or a propositional format of our representations; it is only a third way to approach human intersubjective relations. "Embodied Simulation aims at providing a unitary account of basic aspects of intersubjectivity showing that people reuse their own mental states or processes represented in bodily format to functionally attribute them to others” (Gallese 2013, 2954). 
From a neuroscientific perspective, intersubjectivity deals with brains and bodies, overlapping intercorporeity, namely the relationship between bodies that perceive and recognize each other. This view can be sharpened through a philosophical stance. In his Cartesian Meditations (1931), Edmund Husserl pointed out in the framework of phenomenology, the existence of a perceptive body among other bodies. Furthermore, if moving alone, an individual is always aware of the parts of his body that allow him to experience the world. Considering our bodies among others represents the aim of avoiding the fall of the transcendental ego into solipsism, the reason that the reduction (epochè) of the ego to transcendental ego represents the opening to the dimension of the other, recognizing the other starting from ourselves. Each ego, at the stage of mirroring, has its own alter ego. Ego and alter ego are two psychophysical units provided with Leib (the living body) and Korper (the physical body). The sliding movement from ego into transcendental ego shifts subjective experiences to intersubjective ones through the concept of Paarung, a pairing that warrants the recognizing of the others and their Leib. Husserlian intersubjectivity has a pre-predicative dimension with a symbolic but non-linguistic experiential nature. The phenomenological intersubjectivity is the philosophical forerunner of the neuroscientific concept of embodied simulation.

\subsection{Two Philosophical Remarks on Intentions}

Taking into account Daniel Stern's (1985) research in the field of evolutionary psychology, it is known that a two-month-old baby's facial expressions are synchronized with his mother's facial expressions because of a process called affective attunement. The affective attunement system is similar to the mirroring system and it is directly generated by embodied simulation when a process of mutual recognition is initiated. Intentional attunement is the phenomenal state which allows the establishment of a dynamic relationship between the "I" and the "Thou."

When confronting the intentional behavior of others, we experience a specific phenomenal state of "intentional attunement." This phenomenal state generates a peculiar quality of familiarity with other individuals, produced by the collapse of the others' intentions into the observer's ones. This seems to be one important component of what being empathic is about. (Gallese 2006, 19-20)

Intentional attunement and its generator mechanism of embodied simulation stand on call to the concept of intention, referring generally to the willingness to do something, or act. This definition of intentionality lacks the sharpness of philosophical investigation. Here, I will provide two remarks on philosophical intentionality connected to the mirror neuron system and the embodied simulation mechanism.

At the risk of sounding overly simplistic, one might point out that creating an intersubjective dimension deals with intentions. A previous phenomenological review about intersubjectivity recalls the cruciality of the concept of intentionality. In fact, starting from Brentano, Husserl defined intentionality as the power of consciousness to refer to something, namely to be directed toward something. The classical example is that of perception as an act of consciousness; to perceive is always perceiving something. The intentional relation between consciousness and "something" is the philosophical mechanism that justifies the relationship between ego and alter ego, which constitutes a community of intentional ego.

The motor goals and intentions identified by the activity of the mirror mechanism are consistent with the scheme of Husserlian intentionality. However, in my opinion, the phenomenological aspects of intentionality do not completely represent the sense of intentionality provided by mirror neurons. Mirror neurons refer to a kind of intentionality that is the ability to infer the purpose of an action, its meaning, and the chance to comprehend the willingness of a motor action. For this reason, some scholars (Jacob and Jannerod 2005) argue against the role of 
mirror neurons for the comprehension of communicative intentions. Then, the question falls under the notion of communicative intention and its relationship with meaning.

The philosophy of language proposes (at least) another kind of intentionality linked to verbal communication that needs to be taken into account. How do intentions matter in the meaning of a sentence? Paul H. Grice, proposing intention-based semantics (1957, 1968, 1975), argued for a theory of meaning based on the communicative intentions of sign users, without distinction between verbal and non-verbal signs. The cornerstone of Grice's theory is that meaning coincides with wanting to tell something, making the distinction between what the speaker says and what the speaker wants to say (Grice 1975). The real evidence of the "speaker's intention meaning" is understood with conversational implicatures, that is, all the information that the literal meaning of an utterance does not explicitly convey but is still communicated by the speaker insofar as the listener can rebuild its meaning. According to Grice, we are able to express more than we can tell and the listener has to be able to logically infer the meaning of what is "not said.” Implicatures and the conversational context play crucial roles in the meaning of utterances. The communicative relationship between utterers is dialogue as a cooperative practice driven by purpose.

A community does not argue only for communication but also for a cooperative effort that aims to be of benefit to the same community. Stating that linguistic exchange is a cooperative work, Grice speaks about the same effort ruled by the principle of cooperation. The kind of intentionality that underpins the logical inference supported by Grice can be found in the motor intentionality that mirror neurons catch. It is true that simulation is the non-logical process that rules inference through comprehension of the motor purpose and this process is pre-riflessive, immediate but —at the same time - the executor has a motor intention similar to the speaker's intention. Pragmatic intentionality and motor intentionality do not exclude each other; they can exist together to reflect a complete picture of human nature. In fact, this complex notion of intentionality provides a picture of human nature that in ontogeny and phylogeny stems from our brain and body.

\section{Embodied Simulation and Language}

Research on the mirroring mechanism and embodied simulation has provoked some questions about the nature of language from the neuroscientific point of view, which obviously, from a philosophical point of view, is another attempt to naturalize language. What is the concept of language conceived through the results of experiments and empirical data by a neuroscientist involved in mirror neurons?

A great deal of empirical data show that the system of mirror neurons activates when one listens to sentences that contain motor verbs, that is, that mirror neurons play an important role in the comprehension of sentences that describe actions. In this way, studies have shown the inextricable relationship between action, perception and language. Since research on embodied simulation offers some hints about human nature, in order to delve into the relationship between brain, body and the world, one cannot ignore that language is one of the features that relies on the uniqueness of human beings.

Gallese (2007, 2008, 2016, with Eagle and Migone 2007; with Cuccio et al. 2014) tried to apply the results on mirror neurons and embodied simulation to language, sometimes working with Italian philosophers of language. In his earlier studies $(2007,2008)$ involving language, Gallese provided an account of the social nature of language starting with the nature of mirror neurons. Following the perspectives of Merleau-Ponty and Heidegger about meaning, Gallese maintains that meaning "emerges from a peculiar historical world to which humans are connected through their daily interactions with it" and that 
[o]ur understanding of the meaning of a word like "table" does not stem from our use of a linguistic game, which, at best, can specify when to apply a given word as a tag to a given object in the world. The meaning of "table" stems from its use, from what we can do with it, that is, from the multiple and interrelated possibilities for actions it evokes. (Gallese 2008, 322)

Holding Heidegger's idea of language, Gallese rejects the idea of Wittgenstein's linguistic game, comparing the sense of a linguistic game with the chance to assign a tag to the things of the world. However, the idea that Gallese attributes to the concept of a linguistic game is extremely limited and does not grasp that the core of the linguistic game is the notion of the use of language, which in turn will be reconsidered explicitly in future research. According to the phenomenological perspective, Gallese states: "Our understanding of linguistic expressions is not solely an epistemic attitude; it is a way of being... Our way of being, in turn, depends on what we act, how we do it, and how the world responds to us" (Gallese 2008, 322). Then, without being fully philosophically aware, this neuroscientific view on language is closer to the concept of use than is recognized.

The concept of use has been reconsidered due to the joined research of the neuroscientists of Parma and philosophers of language of the University of Palermo; "[T]he activation of the sensorimotor system is always a necessary condition to comprehend language, at least when language refers to the domains of action and perception” (Cuccio, Ambrosecchia, Ferri, Carapezza, Lo Piparo et al. 2014, 2) and contextual information plays a crucial role. The context is composed of the hypothesis we made of the (part of the) world we are experiencing and it is given by informations on the physical environment, the place of conversation, the speakers (including their knowledge), and all the utterances they have produced before and during the dialogue. The context is a useful sphere within which to imbue meaning to words and sentences. The philosophical speculation on the active role of the speaker and the listener in the making of meaning is empirically shown experimentally, understanding that contextual information and embodied simulation are strictly connected. One of the conclusions to be further investigated is that language evolved from (manual) gestures, connecting the pre-linguistic (but communicative) domain to the linguistic one.

Aware of the impossibility to liquidate the issue of language, Gallese tries, on a speculative level, to claim the relationship between language and the Lieb, matching neuroscience and philosophy. Recalling Aristotle's paradeigma $^{9}$ and Agamben's rereading, Gallese purports a hypothesis about the role of embodied simulation as a paradigm when living our experiences. Language is the way we fix and relive our experiences without referring immediately to the physical context, but connecting to the original I-Thou relationship. In the light of paradeigma, my experience is the example, the known case, which allows the understanding of the experience of the other.

\section{Some Suggestions for Philosophy of Language and Neuroscience in Italy}

My review of Italian research on the mirror neuron system shows a great interest in language, considering an unavoidable feature to be studied in the broader framework of embodied simulation in order to cut off the domain of social cognition. First, it should be pointed out that in Gallese's research, there is no unique reference to language; the term is used to refer to the faculty of language and in a pragmatic view, to indicate languages: "The faculty of language is therefore, on one side, rooted in corporeity but, in turn, it changes and shapes our way of living bodily experiences” (Gallese 2016, 307). 
Why does neuroscience try to explain issues that refer to language? And conversely, why do those who work on language need neuroscience?

In this paper, the joint research of neuroscientists and philosophers of language is an example of how science and the humanities could work to bring out scientific results to more accurately define human nature. Similarly, in the past few years, a research group studying mirror neurons has been searching together with academics in the field of aesthetics to understand how we are tuned to the characters and stories we watch at the cinema. Currently, Gallese is working with researchers of different fields to develop his neurohumanistic approach. No one can exclude future research on the reception of artworks and in the field of the semiotics of design. This example of research in Italy shows that the sceptical perspective of scholars like Ferretti (2015) does not necessarily mark the future. Obviously, the examples provided here are not standard in the frontiers of research but can be seen as a first attempt for a new and fruitful research path.

I will now provide two research recommendations suggested by the work of Gallese and his interest in language which can only be developed with the assistance of philosophers of language.

The first research theme refers to intentionality and the paradeigma of intentional attunement and should involve Italian philosophers of language who are interested in the concept of enunciation and dialogue. One of the possible meanings of the sociality of language is the intersubjective dimension that we find through the phenomenology of Husserl, if the latter is not involved in predicative dimension. The space of intersubjectivity is not only a place where bodies interact, but also a place for dialogue, which-according to the French linguist Emile Benveniste-is the condition of human language within the presence of society. "We speak to others who speak to us: such is the nature of human intercourse... Now the characteristic of language is to produce a substitute for experience which can be passed on ad infinitum in time and space" (Benveniste 1966 trad. en. 1971, 53). Society is a community of speakers and each of them, in linguistic practice, has the chance to place himself as the subject: "Language is possible only because each speaker sets himself up as a subject by referring to himself as $I$ in his discourse. Because of this, $I$ posits another person, the one who, being, as he is, completely exterior to 'me,' becomes my echo to whom I say you and who says you to me” (Benveniste 1966 trad. en. 1971, 225).

The two focal points $I$ and you tend to meet exceeding one into the other and vice versa, giving rise to a shared space in which we find a sense of collectivity. This reflection on language as the whole space in which we find a biological faculty, all languages and "language—as—institution" finds its empirical value in each language we speak, because, following Benveniste, there has never been a spoken language that does not refer explicitly to the person. Every time there is the occurrence of an $I$ and you dialogue, a linguistic game is played that allows the exchange of roles in new and different ways, recreating itself in the precise time in which the language exercise occurs. The exchange between I and you bounds the space of dialogue and defines a shared, intersubjective place, in the same way, in a phenomenological path, we have a Paarung, a pairing of ego and alter ego that Gallese called intentional attunement.

The second suggestion refers to the employment of the concept of context in research on embodied simulation. Certainly, the starting point is the research I have mentioned in the previous sections, but to strongly show how context is interfered in embodied simulation, it is necessary to use all the insights of the pragmatics of language, which is a research field in the philosophy of language in Italy that includes both philosophers interested in general linguistics and analytic philosophers of language. Because of the dynamicity of the context, the way it modulates embodied simulation could affect the relationship between speakers and linguistic 
activities, such as denying or asking, which are rooted in our bodies. This point deserves further investigation in order to clarify the connection between intentional attunement and context. Moreover, recalling the notion of context is always related to a particular situation and includes a sense of corporeity and intercorporeity between speakers leads us to a question about a wider range of linguistic utterances than the ones directly involving motor verbs.

Finally—a brief speculation about a theme that might provide a common ground for research: In the first section, I outlined the fragmented scene of philosophy in Italy, which is a result of the contributions of philosophers who have been interested over the years in trying to analyse their respective research fields. While for decades, in Italy, science and philosophy have been separated, many research themes need a joint thinking to deeply understand human nature. Social cognition, language and languages, non-verbal communication, and the origin and evolution of language, sometimes supported by the wide notion of practice, share the field with scientific research. The concept of activity and practice is the key point for future joint researchers. In Italy, philosophers of language are ready to begin investigating with neuroscientist, starting from the so-called linguistic school of Rome in the shadow of Tullio De Mauro.

\section{Notes} 2009.

1. See Antonio Negri in The Italian Difference: Between Nihilism and Biopolitics, L. Chiesa and A. Toscano (eds.), re-press,

2. Prospettive di teoria del linguaggio (E. Fava, P. Leonardi, R. Galassi, M. Sbisà eds.), Unicopli, 1983 is a complete examination of the lines of research and schools in Philosophy of Language up to 1983. Recently, Claudia Stancati (2015) outlined the main theoretical knots of the three main perspectives in the Italian philosophy of language and their historical developments. At the same time, Francesco Ferretti (2015) explores the relationship between Philosophy of Language and Cognitive Sciences, highlighting that relevant shared research is prevented by a kind of Philosophy of Language that is nearly a History of Philosophy with deep-seated anti-mentalist and anti-naturalist attitudes. Another obstacle is the strong division between Science and Philosophy and the lack of joint ventures between different research fields.

3. Claudia Stancati (2015) points out that many philosophers of language are interested in rhetoric and theory of argumentation and the research of many philosophers interested in aesthetics, phenomenology, and French and German thought are concerned with language.

4. Rivista Italiana di Filosofia del Linguaggio is an online only (http://www.rifl.unical.it) peer-reviewed journal which publishes articles, interviews, and book reviews concerning language. The journal shows an interdisciplinary approach that is open to many traditions: Philosophy, Semiotics, Psychology, Psychoanalysis and Epistemology. In spite of the subdivision of the Philosophy of Language into three research perspectives, this journal offers an approach of synthesis and comparison.

5. Since the focus is the Italian context, I will refer mainly to the researches carried out at the University of Parma. However, to have an overall view, see the following critique (Hickock 2014).

6. Translation mine. Original text: "Non ci limitiamo a vedere con la parte visiva del nostro cervello, ma utilizziamo anche il nostro sistema motorio" in Gallese, Vittorio, 2007, "Sintonizzazione intenzionale: simulazione incorporata e suo ruolo nella cognizione sociale,” in Mancia M. (ed.), Psicoanalisi e neuroscienze, Springer Verlag Italia, Milano.

7. See section 3.1.

8. I am referring to the simulation theory of mind reading (see Goldman 2006).

9. The Aristotelian paradeigma is an argument based on an example which moves from individual to individual. This argument is used to show something that is little-known starting from something that is well-known.

\section{Works Cited}

Benveniste, Émile, Problems in General Linguistics. French original edition 1966. Miami: University of Miami Press, 1971. Buongiorno, Federica and Lucci, Antonio (eds.). “La Differenza Italiana. Filosofi(e) nell’Italia di Oggi.” Lo Sguardo—Rivista di Filosofia II/15 (2014): 5-7. 
Chiesa, Lorenzo and Toscano, Antonio (eds.). The Italian Difference: Between Nihilism and Biopolitics. Melbourne: Re-press, 2009.

Cimatti, Felice. “Dal linguaggio al corpo.” Lo Sguardo—Rivista di Filosofia II/15 (2014): 149-64.

---. “Italian Philosophy of Language.” Rivista Italiana di Filosofia del Linguaggio 9.1 (2015): 14-36.

Cimatti, Felice and Piazza, Francesca (eds.). Filosofie del linguaggio. Roma: Carocci, 2016.

Cuccio, Valentina, Ambrosecchia, Marianna, Ferri, Francesca, Carapezza, Marco, Lo Piparo, Franco, Fogassi, Leonardi, Gallese, Vittorio. "How the Context Matters. Literal and Figurative Meaning in the Embodied Language Paradigm.” Plos ONE 9.12 (2014): e115381. Doi:10.1371/journal.pone.0115381.

Esposito, Roberto. Living Thought. The Origins and Actuality of Italian Philosophy. Italian original edition 2010. Stanford: Stanford University Press, 2012.

---. “Che cos'è Italian Theory? Tavola rotonda con Roberto Esposito, Dario Gentili, Giacomo Marramao.” Lo Sguardo—Rivista di Filosofia 15 II (2014): 11-24.

---. “Vie biologique et vie politique.” Rue Descartes 4/87 (2015): 44-57.

Fava, Elisabetta, Galassi, Romeo, Leonardi, Paolo and Sbisà, Marina. Prospettive di teoria del linguaggio. Milano: Unicopli, 1983.

Ferretti, Francesco. "Philosophy of Language and Cognitive Science in Italy.” Rue Descartes 4/87 (2015): 35-43.

Gallese, Vittorio, Fadiga, Luciano, Fogassi Leonardi and Rizzolatti Giacomo. “Action Recognition in the Premotor Cortex.” Brain 119 (1996): 593-609.

Gallese, Vittorio. "Intentional Attunement: A Neurophysiological Perspective on Social Cognition and Its Disruption in Autism.” Brain Research 1079.1 (2006): 15-24.

---. “Sintonizzazione Intenzionale: Simulazione Incorporata e suo Ruolo nella Cognizione Sociale.” Ed. Mancia M. Psicoanalisi e Neuroscienze. Milano: Springer Verlag Italia, 2007. 285-319.

---."Mirror Neurons and the Social Nature of Language: The Neural Exploitation Hypothesis.” Social Neuroscience 3.3 (2008): 317-33.

---."Mirror Neurons, Embodied Simulation, and the Neural Basis of Social Identification.” Psychoanalytic Dialogues 19 (2009): 519-36.

---. “Mirror Neurons, Embodied Simulation and a Second-Person Approach to Mindreading.” Cortex 49.10 (2013): $2954-6$.

---. "Finding the Body in the Brain. From Simulation Theory to Embodied Simulation.” In Goldman and His Critics. New York: John Wiley and Sons Inc., 2016. 297-314.

Gallese, Vittorio, Eagle Morris, Migone Paolo. "Intentional Attunement: Mirror Neurons and the Neural Underpinnings of Interpersonal Relations.” Journal of American Psychoanalytic Association 55/1 (2007): 131-76.

Gallese, Vittorio and Sinigaglia, Corrado. "What Is So Special about Social Cognition?” Trends in Cognitive Sciences 15.11 (2011): 512-9.

Gentili, Dario. Italian Theory. Dall'operaismo alla biopolitica. Bologna: Il Mulino, 2012.

Goldman, Alvin I. Simulating Minds: The Philosophy, Psychology, and Neuroscience of Mindreading. Oxford: Oxford University Press, 2006.

Grice, Paul. “Meaning.” Philosophical Review Vol. 66 n. 3 (1957): 377-88.

---. “Utterer’s Meaning, Sentence Meaning and Word Meaning.” Foundations of Language 4 (1968): 225-42.

---. "Logic and Conversation.” Eds. Cole, Peter and Morgan Jerry. Syntax and Semantics 3: Speech Acts. New York: Academic Press, 1975. 41-58.

Hickock, Gregory. The Myth of Mirror Neurons. New York: W. W. Norton \& Company, 2014.

Husserl, Edmund. Cartenische Meditationen und Pariser Vorträge. Dordrecht: Kluwer Academic, 1931.

Jacob, Pierre and Jeannerod, Marc. “The Motor Theory of Social Cognition: A Critique.” Trends in Cognitive Sciences 9.1 (2005): 21-25.

Marramao, Giacomo. “Che cos’è Italian Theory? Tavola rotonda con Roberto Esposito, Dario Gentili, Giacomo Marramao.” Lo Sguardo—Rivista di Filosofia 15 II (2014): 11-24.

Paltrinieri, Luca. “Conclusions. Le conflitinfinit.” Rue Descartes 4/87 (2015): 180-7.

Quintili, Paolo. “Péninsule, Archipel, Déterritorialisation. Où Va Le Philosopher Italien?” Rue Descartes 4/87 (2015): 1-9.

Saussure, Ferdinand. De. Course in General Linguistics. La Salle: Open Court, French original edition, 1922.

Stancati, Claudia. “La Philosophie du Langage en Italie Aujourd'hui.” Rue Descartes 4/87 (2015): 58-69.

Stern, Daniel. The Inter Personal World of the Infant. New York: Basic Books, 1985. 